Artigo original

Hegemonia - Revista Eletrônica do Programa de Mestrado em Direitos Humanos, Cidadania e Violência/Ciência Política do Centro Universitário Unieuro

ISSN: $1809-1261$

UNIEURO, Brasília, número 22 (Especial), 2017, pp. 74-97.

Recebido em: 18/7/2017

Avaliado em: 12/8/2017

Aceito em: 29/8/2017

\title{
ELE NO PESCOÇO: A violência simbólica de Pierre Bourdieu e o uso de coleira por parte das mulheres durante o carnaval
}

\author{
Rodrigo Duhau ${ }^{1}$ e Iolanda Bezerra dos Santos Brandão ${ }^{2}$
}

Resumo: Este artigo pretende discutir o conceito de violência simbólica presente na extensa obra do sociólogo francês Pierre Bourdieu. Para isso, será analisado o uso da coleira por parte das mulheres com o nome de seus companheiros, durante os desfiles de carnaval. No caso deste trabalho, a violência simbólica está relacionada ao poder e à dominação que o homem (dominante) tem sobre a mulher (dominada). Essa soberania é perpetuada pelo sexo feminino que, sem perceber, a naturaliza. O trabalho traz, também, informações dos homicídios de mulheres no Brasil. A ideia é apresentar a discussão sobre a violência "espiritual", mas sem se esquecer da violência física que acomete milhares de mulheres.

Palavras-chave: violência simbólica, coleira, dominação.

Abstract: This article discusses the concept of symbolic violence in the extensive work of the French sociologist Pierre Bourdieu. For this, the use of the collar for women with the name of his companions during the Carnival parades will be analyzed. In the case of this work, the symbolic violence is related to power and domination that man (dominant) has on women (dominated). This sovereignty is perpetuated by women who, without realizing it, naturalizes. The work also brings current information of female homicides in Brazil. The idea is to bring the discussion about the "spiritual" violence, but without forgetting the physical violence that affects thousands of women.

Keywords: symbolic violence, collar, domination.

Introdução

O Sistema de Informações de Mortalidade (SIM) da Secretaria de Vigilância em Saúde (SVS) do Ministério da Saúde (MS), entre 2003 e 2013, mostra que o número de homicídio de

\footnotetext{
${ }^{1}$ Mestrando em Ciência Política no Centro Universitário Unieuro.

2 Professora do Centro universitário Unieuro
} 
Artigo original

Hegemonia - Revista Eletrônica do Programa de Mestrado em Direitos Humanos, Cidadania e Violência/Ciência Política do Centro Universitário Unieuro

ISSN: 1809-1261

UNIEURO, Brasília, número 22 (Especial), 2017, pp. 74-97.

mulheres passou de $3.937^{3}$ para 4.762 , um incremento de $21 \%$ na década. Em relação ao último número, isso equivale a 13 assassinatos femininos por dia. Considerando o crescimento da população feminina, que, na década analisada, foi de 89,8 milhões para 99,8 milhões (crescimento de 11\%), tem-se que a taxa nacional de homicídio, que em 2003 era de 4,4 por 100 mil mulheres, alcançou 4,8 em 2013, o que equivale a um crescimento de $8,8 \%$ em dez anos.

Para analisar a influência da Lei $\mathrm{n}^{\circ}$ 11.340/2006, conhecida como Lei Maria da Penha, o estudo se deu da seguinte forma: houve uma separação de dois períodos (1980/2006 e 2006/2013). No primeiro recorte, antes da lei, o crescimento do número de homicídios de mulheres foi de 7,6\% ao ano. Quando ponderado de acordo com a população feminina, o aumento das taxas no mesmo período alcançou $2,5 \%$ ao ano. No segundo recorte, com a lei em vigor, o crescimento dos assassinatos caiu para $2,6 \%$ ao ano e o das taxas diminuiu para $1,7 \%$ ao ano.

De acordo com as estatísticas divulgadas pelo Mapa da Violência 2015, o Brasil, com sua taxa de 4,8 homicídios por 100 mil mulheres, ocupa a quinta posição ${ }^{4}$ num grupo de 83 países com dados homogêneos e que foram fornecidos pela Organização Mundial da Saúde. Em relação a outras localidades, o Brasil tem 48 vezes mais homicídios femininos que o Reino Unido; 24 vezes mais que Irlanda ou Dinamarca; e 16 vezes mais que Japão ou Escócia.

Em relação aos agressores, o estudo aponta que, levando-se em conta jovens e adultas, de 18 a 59 anos, o agressor principal é o parceiro ou ex-parceiro, concentrando a metade de todos os casos registrados. Em referência às idosas, o principal agressor foi um filho, com 35\% dos casos registrados.

No conjunto de todas as faixas, vemos que prepondera largamente a violência doméstica. Parentes imediatos ou parceiros e exparceiros são responsáveis por $67,2 \%$ do total de atendimentos. (WAISELFISZ, 2015, p.48)

\footnotetext{
${ }^{3}$ Os dados colocados neste artigo podem ser encontrados em WAISELFISZ, Julio Jacobo. Mapa da Violência 2015 - Homicídio de Mulheres no Brasil. Brasília: Flacso, 2015.

${ }^{4}$ Apenas El Salvador, Colômbia, Guatemala e Rússia apresentam taxas superiores às do Brasil.
} 
Artigo original

Hegemonia - Revista Eletrônica do Programa de Mestrado em Direitos Humanos, Cidadania e Violência/Ciência Política do Centro Universitário Unieuro

ISSN: 1809-1261

UNIEURO, Brasília, número 22 (Especial), 2017, pp. 74-97.

Os dados trazem uma realidade que preocupa e que precisa ser discutida pelos diversos setores da sociedade. Entretanto, esse debate e essa discussão precisam perpassar por outros tipos de violência, que não está relacionada a socos, a pontapés e ao homicídio de mulheres. O assédio, por exemplo, é um deles. E esse abuso contra o sexo feminino acontece em diferentes lugares, em diferentes situações. Em Brasília (DF), no metrô, há vagões destinados apenas ao sexo feminino para que se evite que a mulher seja tocada sem sua permissão, conforme prevê a Lei no 4848/2012. Na mídia, pululam notícias sobre mulheres que foram ou estão sendo assediadas por homens que se julgam superiores a elas apenas por serem famosos e por terem uma carreira de sucesso na televisão.

Mas há, também, a violência simbólica. E é esse tipo de violência que este trabalho discutirá a partir de mulheres que utilizam coleiras com os nomes dos seus companheiros durante um dos festejos mais importantes do calendário brasileiro - o carnaval.

Neste artigo, serão destacados os seguintes tópicos. O primeiro envolve a violência simbólica, relacionando-a ao conceito de poder simbólico. A ideia é apontar como o sociólogo francês Pierre Bourdieu apresenta essas questões. A partir daí, parte-se para a análise do uso das coleiras com o nome dos parceiros pelas mulheres durante o carnaval. A hipótese é que essa utilização seria uma forma de o sexo feminino, sem perceber, perpetuar a dominação masculina e naturalizá-la.

Essa pesquisa utilizará a indução, que apresenta duas formas: completa ou formal, estabelecida por Aristóteles. Esta, conforme Marconi e Lakatos (2003), não induz de alguns casos, mas de todos, sendo que cada um dos elementos inferiores é comprovado pela experiência. Conforme a autora, como esta espécie de indução não leva a novos conhecimentos, é estéril, não passa de um processo de colecionar coisas já conhecidas e, portanto, não tem influência (importância) para o progresso da ciência.

A outra indução é incompleta ou científica, criada por Galileu e aperfeiçoada por Francis Bacon. Marconi e Lakatos explicam que essa indução não deriva de seus elementos inferiores, enumerados ou provados pela experiência, mas permite induzir, de alguns casos adequadamente observados (sob circunstâncias diferentes, sob vários pontos etc.), e, às vezes, de uma só observação, aquilo que se pode dizer (afirmar ou negar) dos restantes da mesma categoria. Portanto, para os autores, a indução científica fundamenta-se na causa ou na lei que rege o fenômeno ou fato, constatada em um número significativo de casos (um ou 
Artigo original

Hegemonia - Revista Eletrônica do Programa de Mestrado em Direitos Humanos, Cidadania e Violência/Ciência Política do Centro Universitário Unieuro

ISSN: 1809-1261

UNIEURO, Brasília, número 22 (Especial), 2017, pp. 74-97.

mais), mas não em todos. E é esse tipo de indução que será usada nesse trabalho. Ou seja, a parte (mulheres que usam coleira) para explicar o todo (o sexo feminino, que sem perceber, age como colaborador da dominação masculina).

Serão utilizadas as seguintes fontes para fundamentar esse artigo: referências bibliográficas, com destaque para os conceitos destacados por Bourdieu, e matérias jornalísticas disponibilizadas na internet em canais informativos.

A violência simbólica

Nascido em 1930 em Denguin, uma aldeia francesa, Pierre Bourdieu é considerado um dos maiores sociólogos do século XX. Estudou em Paris, viajou para a Argélia quando teve de cumprir o serviço militar obrigatório e escreveu diversos livros. Seus estudos questionaram correntes mais influentes no campo filosófico, entre elas o Marxismo, e contribuíram para o entendimento da dominação e como se gera a desigualdade numa sociedade complexa do capitalismo avançado.

Em relação ao Marxismo, Bourdieu desacreditava do fato de que a sociedade estava dividida em duas classes: a burguesa e a proletária. O sociólogo francês ressalta que a classe social não deve ser explicada apenas pelos meios de produção, mas, sim, por intermédio de uma embaraçada rede de relações. Bourdieu, também, discutiu conceitos, configurando-os, amplificando-os, como são os casos de "campo", "capital" e "habitus"7. Para ele, o sociólogo é um intelectual que não assume o papel dos oprimidos, mas lhes oferece os argumentos para lutar contra a dominação, a opressão, a injustiça e a violência.

Um dos conceitos mais presentes nos estudos de Bourdieu é o que trata de o poder simbólico. Para o sociólogo, esse fenômeno está em todos os lugares e que, por isso,

\footnotetext{
${ }^{5}$ De forma bem resumida, Bourdieu entende que campo é o espaço - cultural, econômico, educacional, científico -, no qual é determinada a posição social dos agentes e onde se revelam, por exemplo, as figuras de "autoridade" detentoras de maior volume de capital.

${ }^{6} \mathrm{O}$ sociólogo francês entende por esse termo não apenas o acúmulo de bens e riquezas econômicas, mas todo poder que se manifesta em uma atividade social. Além do capital econômico, Bourdieu acredita ser fundamental a compreensão de capital cultural e capital social. Ou seja, desigualdades sociais não aconteceriam somente devido às desigualdades econômicas.

${ }^{7}$ Para Bourdieu, é um sistema de disposições, ações e percepções que os indivíduos adquirem com o tempo por intermédio de suas experiências na sociedade. O habitus traduz linguagem corporal, regras de cortesia, juízos de valor morais e estéticos, entre outros.
} 
Artigo original

Hegemonia - Revista Eletrônica do Programa de Mestrado em Direitos Humanos, Cidadania e Violência/Ciência Política do Centro Universitário Unieuro

ISSN: 1809-1261

UNIEURO, Brasília, número 22 (Especial), 2017, pp. 74-97.

trata-se de um trabalho fundamental descobri-lo onde esse poder menos aparece, onde ele é ignorado, portanto, reconhecido.

O poder simbólico é, com efeito, esse poder invisível o qual só pode ser exercido com a cumplicidade daqueles que não querem saber que lhes estão sujeitos ou mesmo que o exercem. (BOURDIEU, 1989, p.7)

O poder simbólico seria um instrumento de construção da realidade e que está relacionado aos sistemas simbólicos. Esses impõem ou legitimam uma dominação, além de contribuírem para assegurar a influência de uma classe sobre a outra (violência simbólica), contribuindo assim para aquilo que Max Weber (1999) chamou de "domesticação dos dominados". Além disso, os sistemas simbólicos só “domesticam” porque são, ao mesmo tempo, estruturantes (edificam uma verdade) e estruturados. Essa construção de uma visão de mundo está imbricada com os interesses da classe dominante, aquela que detém maior capital no sentido que Bourdieu dá ao conceito.

As ideologias, por oposição ao mito, produto coletivo e coletivamente apropriado, servem interesses particulares que tendem a apresentar como interesses universais, comuns ao conjunto do grupo. A cultura dominante contribui para a integração real da classe dominante (assegurando uma comunicação imediata entre todos os seus membros e distinguindo-os das outras classes); para a integração fictícia da sociedade no seu conjunto, portanto, à desmobilização (falsa consciência) das classes dominadas; para a legitimação da ordem estabelecida por meio do estabelecimento das distinções (hierarquias) e para a legitimação dessas distinções. (BOURDIEU, 1989, p.10) 
Artigo original

Hegemonia - Revista Eletrônica do Programa de Mestrado em Direitos Humanos, Cidadania e Violência/Ciência Política do Centro Universitário Unieuro

ISSN: $1809-1261$

UNIEURO, Brasília, número 22 (Especial), 2017, pp. 74-97.

Ainda sobre o poder simbólico, Bourdieu ressalta sua capacidade de constituir o dado pela enunciação, de fazer a classe dominada ver e crer aquilo que interessa aos dominantes, de transformar, de criar o mundo.

Poder quase mágico que permite obter o equivalente daquilo que é obtido pela força (física ou econômica), graças ao efeito específico de mobilização, só se exerce se for reconhecido, quer dizer, ignorado como arbitrário. (BOURDIEU, 1989, p.14)

A violência simbólica só se apresenta devido a uma relação de poder. Ou seja, é preciso que haja um opressor e um oprimido, que não reconhece tal opressão, tal arbitrariedade e, além disso, a naturaliza. Um bom exemplo é o convívio entre homem e mulher. Para Bourdieu, pode-se tratar de uma violência suave, insensível, invisível a suas próprias vítimas, que se exerce essencialmente pelas vias puramente simbólicas da comunicação e do conhecimento, ou, mais precisamente, do desconhecimento, do reconhecimento ou, em última instância, do sentimento.

Segundo Abramovay et al (2009), é considerada violência simbólica aquela que se realiza através de símbolos e signos culturais, se constituindo numa forma de dominação que se ampara em mecanismos simbólicos de poder a fim de fazer com que as pessoas em situação de violência não compreendam tal conjuntura como violência, aceitando-a.

Em diferentes contextos históricos, podem ser encontradas inúmeras sociedades nas quais o patriarcalismo prevalece. A figura do macho é a que domina, a que prevalece, a que realiza as tarefas consideradas mais nobres, a que, de certa forma, escanteia a fêmea, relegando-a às ações simplórias, escondidas e impostas pela cultura masculina.

Em sua viagem à Argélia, Bourdieu teve a oportunidade de conhecer um pouco mais sobre aquela sociedade enquanto cumpria o serviço militar. Devido a isso, produziu importantes trabalhos sociológicos. Em 1962, publicou o livro Na Argélia, um estudo sobre o trabalho assalariado e a formação do proletariado urbano daquele país. Já na obra $A$ dominaşão masculina, publicada em 1998, o sociólogo francês discute o domínio dos homens em Cabília, pequena cidade na Argélia.

Em Uma imagem ampliada, primeiro capítulo do livro $A$ dominação masculina, Bourdieu analisa essa violência simbólica que o homem exerce sobre a mulher. Ele investiga 
Artigo original

Hegemonia - Revista Eletrônica do Programa de Mestrado em Direitos Humanos, Cidadania e Violência/Ciência Política do Centro Universitário Unieuro

ISSN: 1809-1261

UNIEURO, Brasília, número 22 (Especial), 2017, pp. 74-97.

a visão social em Cabília e a relaciona com a anatomia do "macho" e da "fêmea". A partir da cidade argelina, o sociólogo discute essa hierarquização, que invariavelmente pende para o lado masculino da relação. Uma hierarquização tão presente em diferentes sociedades e em diferentes contextos históricos.

Bourdieu fala de uma relação circular, onde o contexto social classifica e hierarquiza os órgãos genitais masculino e feminino e que estes também influenciam a vida em sociedade. Conforme as análises do sociólogo francês, os camponeses das montanhas da Cabília mantiveram estruturas que representam uma forma paradigmática da visão "falonarcísica" e da cosmologia androcêntrica, comuns a todas as sociedades mediterrâneas e que sobrevivem nas estruturas cognitivas e sociais da coletividade.

Para Bourdieu,

A diferença biológica entre os sexos, isto é, entre o corpo masculino e o corpo feminino, e, especificamente, a diferença anatômica entre os órgãos sexuais, pode assim ser vista como justificativa natural da diferença socialmente construída entre os gêneros e, principalmente, da divisão social do trabalho. (BOURDIEU, 1998, p.20)

Há uma força da ordem masculina, que, para Bourdieu, não precisa ser justificada. Esse poder se impõe e não necessita de discursos para ser legitimado. "A ordem social funciona como uma imensa máquina simbólica que tende a ratificar a dominação masculina sobre a qual se alicerça.” (BOURDIEU,1998, p.18)

Com a imposição da visão androcêntrica, cria-se terreno para o surgimento de pares de oposição, de representações. Por exemplo, expressões como "alto”, "em cima”, "reto", "duro", "positivo" e "direito" associadas ao homem; e "baixo", "embaixo", "curvo" (falso), "negativo", “do avesso" e "mole” relacionadas à mulher. Vale destacar que, na Idade Média, um cirurgião representou a vagina como um falo invertido e que até o Renascimento não havia terminologia anatômica para descrever em detalhes o sexo feminino. Dizia-se apenas que estava em disposição diversa. Conforme Bourdieu, as diferenças visíveis entre os órgãos sexuais masculino e feminino são uma construção social que encontra sua base nos princípios da razão androcêntrica. E isso também é perceptível no ato sexual. Como Bourdieu pontua, os homens representam a relação sexual como uma forma de dominação, 
Artigo original

Hegemonia - Revista Eletrônica do Programa de Mestrado em Direitos Humanos, Cidadania e Violência/Ciência Política do Centro Universitário Unieuro

ISSN: 1809-1261

UNIEURO, Brasília, número 22 (Especial), 2017, pp. 74-97.

de apropriação, de conquista. Para a mulher, trata-se de uma experiência íntima, afetiva e que não inclui necessariamente a penetração. Até o orgasmo feminino parte de uma visão masculina, pois para o "macho", o fato de a "fêmea" gozar é uma prova da virilidade do homem.

Vale apontar também que a representação é um fenômeno construído e essa edificação, em muitas situações, acontece por meio da classe dominante ou por intermédio de uma autoridade (política, econômica, religiosa, estudantil) que tem um grande poder de formação da opinião pública. Esses modos de ver o outro e de forjar uma realidade a partir de uma perspectiva particular estão embebidos de interesses, de primeiras e segundas intenções, e, ao mesmo tempo, carecem de neutralidade. São tendenciosos, por assim dizer.

Chartier (2002) destaca:

As representações do mundo social assim construídas, embora aspirem à universalidade de um diagnóstico fundado na razão, são sempre determinadas pelos interesses de grupo que as forjam. Daí, para cada caso, o necessário relacionamento dos discursos proferidos com a posição de quem os utiliza. (CHARTIER, 2002, p.17)

Além disso,

As percepções do social não são de forma alguma discursos neutros: produzem estratégias e práticas (sociais, escolares, políticas) que tendem a impor uma autoridade à custa de outros, por elas menosprezados, a legitimar um projeto reformador ou a justificar, para os próprios indivíduos, as suas escolhas e condutas. Por isso, esta investigação sobre as representações supõe-nas como estando sempre colocadas num campo de concorrências e de competições cujos desafios se enunciam em termos de poder e de dominação. (CHARTIER, 2002, p.17) 
Artigo original

Hegemonia - Revista Eletrônica do Programa de Mestrado em Direitos Humanos, Cidadania e Violência/Ciência Política do Centro Universitário Unieuro

ISSN: 1809-1261

UNIEURO, Brasília, número 22 (Especial), 2017, pp. 74-97.

Chartier (2002) explica que as lutas de representações e as lutas econômicas têm a mesma importância. Ambas são fundamentais para tentar entender e perceber por quais mecanismos um grupo impõe, ou tenta impor, a sua concepção do mundo social, os valores que são os seus, e o seu domínio; quais instrumentos, por exemplo, a classe dominante em um determinado contexto utiliza para edificar a realidade que mais lhe convém. Chartier, então, não atribui apenas à economia o papel determinante para analisar aspectos da sociedade, como o Marxismo imputava.

Pesavento (2012) estabelece uma correlação entre o poder simbólico e a maneira de um determinado grupo ver o mundo, ou seja, como esse grupo representa o "real":

As representações apresentam múltiplas configurações, e pode-se dizer que o mundo é construído de forma contraditória e variada, pelos diferentes grupos do social. Aquele que tem o poder simbólico de dizer e fazer crer sobre o mundo tem o controle da vida social e expressa a supremacia conquistada em uma relação histórica de forças. Implica que esse grupo vai impor a sua maneira de dar a ver o mundo, de estabelecer classificações e divisões, de propor valores e normas, que orientam o gosto e a percepção, que definem limites e autorizam os comportamentos e os papéis sociais. (PESAVENTO, 2012, p.41)

As representações são construções e possuem um poder de substituição, além de fazerem que os seres humanos percebam a "realidade" através delas. "São matrizes geradoras de condutas e práticas sociais. [...] Indivíduos e grupos dão sentido ao mundo por meio de representações que constroem sobre a realidade.” (PESAVENTO, 2012, p.39). Por fim, Pesavento lista algumas funções que estão relativas à noção de representação. "A representação envolve processos de percepção, identificação, reconhecimento, classificação, legitimação e exclusão. (PESAVENTO, 2012, p.40.) Para Pesavento (2012), as representações podem ser expressas por normas, instituições, discursos, imagens e ritos. Elas formam uma realidade paralela à existência dos indivíduos, mas fazem os homens viverem por elas e nelas. 
Artigo original

Hegemonia - Revista Eletrônica do Programa de Mestrado em Direitos Humanos, Cidadania e Violência/Ciência Política do Centro Universitário Unieuro

ISSN: $1809-1261$

UNIEURO, Brasília, número 22 (Especial), 2017, pp. 74-97.

Conforme Porto (2009), a condição de falsa ou verdadeira de uma representação é irrelevante. O importante é considerar que as afirmações nela contidas estão difundidas no senso comum, fazem parte dos ditos populares e - o que é mais relevante -, uma vez constituídas como verdade, informam condutas e comportamentos dos atores sociais.

Nessa medida, vale insistir, as representações sociais, em si mesmas, não são nem falsas nem verdadeiras, apenas a matéria-prima, o dado bruto que cabe ao sociólogo analisar, interpretar, compreender. Além disso, não são racionais ou irracionais embora respondam, certamente, por uma racionalidade que as constitui em objeto do conhecimento. Racionalidade de uma natureza distinta totalmente do conhecimento que a ciência proporciona. Para o analista do social, tal produto não pode ser sinônimo do real e sim um dado de realidade que precisa ser submetido à análise como condição de produção de um conhecimento pertinente. (PORTO, 2009, p. 802)

Se as representações são o modo de ver, as práticas culturais seriam o modo de fazer.

O que são as práticas culturais? Antes de mais nada, convém ter em vista que esta noção deve ser pensada não apenas em relação às instâncias oficiais de produção cultural, às instituições várias, às técnicas e às realizações (por exemplo os objetos culturais produzidos por uma sociedade), mas também em relação aos usos e costumes que caracterizam a sociedade examinada pelo historiador. São práticas culturais não apenas a feitura de um livro, uma técnica artística ou uma modalidade de ensino, mas também os modos como, em uma dada sociedade, os homens falam e se calam, comem e bebem, sentam-se e andam, conversam ou discutem, solidarizamse ou hostilizam-se, morrem ou adoecem, tratam seus loucos ou recebem os estrangeiros. (BARROS, 2003, p.157) 
Artigo original

Hegemonia - Revista Eletrônica do Programa de Mestrado em Direitos Humanos, Cidadania e Violência/Ciência Política do Centro Universitário Unieuro

ISSN: $1809-1261$

UNIEURO, Brasília, número 22 (Especial), 2017, pp. 74-97.

Barros complementa que as práticas geram representações e as suas representações geram práticas em um emaranhado de atitudes e gestos no qual não é possível distinguir onde estão os começos (se em determinadas práticas, se em determinadas representações)

Essa construção simbólica, vale ressaltar, não se dá de forma abrupta, súbita. A dominação masculina é uma edificação profunda e duradoura. É uma espécie de adestramento, que começa na infância e que modifica corpos e mentes. Uma das consequências disso pode ser percebida no fato de que os homens desempenham as tarefas mais nobres na sociedade. Para o "macho", atos breves, perigosos, espetaculares, como matar o boi, a lavoura, o homicídio, a guerra, cita Bourdieu. Cabem às mulheres todos os trabalhos domésticos, privados e ocultos.

Hobsbawn, ao analisar a mobilização da massa para os combates das duas guerras mundiais, oferece dados que ratificam o fato de que apenas restam às mulheres os trabalhos caseiros e que o cenário pode mudar de figura unicamente quando se passa por um período de exceção. Nesse caso, elas começam a executar tarefas que até então eram destinadas ao sexo masculino na organização social, fora do ambiente doméstico.

As economias agrárias tradicionais não podem em geral mobilizar uma proporção tão grande de sua força de trabalho, a não ser sazonalmente, pelo menos na zona temperada, pois há momentos no ano agrícola em que todos os braços são necessários (por exemplo, para a colheita). Mesmo em sociedades industriais, uma tão grande mobilização de mão de obra impõe enormes tensões à força de trabalho, motivo pelo qual as guerras de massa fortaleceram o poder do trabalhismo organizado e produziram uma revolução no emprego de mulheres fora do lar: temporariamente na Primeira Guerra Mundial, permanentemente na Segunda Guerra Mundial. (HOBSBAWN, 1995, p.42)

Retornando às análises de Bourdieu, o sociólogo discute o conceito de "violência simbólica”, que está relacionado ao poder simbólico. Isto é, os dominados (no caso, as mulheres) aplicam categorias construídas a partir da perspectiva dos dominantes (os homens) 
Artigo original

Hegemonia - Revista Eletrônica do Programa de Mestrado em Direitos Humanos, Cidadania e Violência/Ciência Política do Centro Universitário Unieuro

ISSN: 1809-1261

UNIEURO, Brasília, número 22 (Especial), 2017, pp. 74-97.

às relações de dominação. Isso faz com que essa dominação ganhe aspectos de uma naturalidade. Além disso, esse fato pode levar a uma autodepreciação ou autodesprezo da mulher e do seu sexo, tido como algo deficiente, feio e até repulsivo, como destacado na comunidade cabila.

Conforme Bourdieu, essa violência simbólica é um produto de um trabalho incessante de reprodução para o qual contribuem agentes específicos e instituições, entre elas a família, a Igreja, a escola e o Estado. Não raro é possível escutar em cerimônias de casamentos expressões que contribuem a sedimentação da violência simbólica, como, por exemplo, "mulher, quando homem sair do banho, os chinelos dele têm de estar na porta do banheiro" ou "em um matrimônio, o homem é a parte racional; e a mulher, a emocional".

A força simbólica é uma forma de poder que se exerce sobre os corpos, diretamente, e como que por magia, sem qualquer coação física; mas essa magia só atua com o apoio de predisposições colocadas, como molas propulsoras, na zona mais profunda dos corpos. (BOURDIEU, 1998, p. 50)

De acordo com Bourdieu, as mulheres são vistas como objetos, isto é, como símbolos cujo sentido se constitui fora delas e cuja função é contribuir para a perpetuação ou o aumento do capital simbólico em poder dos homens. Para o sociólogo, é nas relações de parentesco e do casamento que se impõe às mulheres seu estatuto social de objeto de troca, estatuto que é definido pela conveniência do "macho".

É possível estabelecer uma relação entre os apontamentos de Bourdieu e Pierre Clastres, antropólogo francês, que discutiu a guerra nas sociedades primitivas. Para Clastres, a sociedade primitiva não vive um ambiente de amizade generalizada, mas também não vive um ambiente de conflito generalizado.

Segundo os escritos do antropólogo, a amizade generalizada entre as comunidades primitivas é impossível. Primeiro, devido à dispersão espacial, ou seja, as relações amistosas de troca só se constroem com grupos próximos. Os mais distantes seriam estrangeiros. Além disso, relações amistosas generalizadas, conforme Clastres, pressupõem uma amizade de todos com todos e uma identificação de todos com todos, o que contrariaria 
Artigo original

Hegemonia - Revista Eletrônica do Programa de Mestrado em Direitos Humanos, Cidadania e Violência/Ciência Política do Centro Universitário Unieuro

ISSN: $1809-1261$

UNIEURO, Brasília, número 22 (Especial), 2017, pp. 74-97.

a lógica da comunidade primitiva, que é uma lógica da diferença, uma lógica de que cada comunidade teria sua própria identidade.

Clastres também desconstrói a hipótese de guerra generalizada na sociedade primitiva.

Qual seria nesse caso o efeito principal da guerra de todos contra todos? Ela instituiria essa relação política cuja emergência a sociedade primitiva procura justamente impedir, a guerra de todos contra todos levaria ao estabelecimento [...] da relação de poder que o vencedor poderia exercer pela força sobre o vencido. [...] Em outras palavras, seria a morte da sociedade primitiva enquanto ela é e quer ser um corpo indiviso. Por conseguinte, a guerra generalizada produziria exatamente o mesmo efeito que a amizade generalizada: a negação do ser social primitivo. No caso da amizade de todos com todos, a comunidade perderia, por dissolução de sua diferença, sua propriedade de totalidade autônoma. (CLASTRES, 2004, p.178)

Portanto, para Clastres, o ser social primitivo seria uma espécie de composto de dois elementos heterogêneos - um pouco de troca, um pouco de guerra. $\mathrm{O}$ estado da arte seria o equilíbrio. É aí que é possível estabelecer um diálogo entre o antropólogo francês e o sociólogo francês. Conforme Clastres, a comunidade primitiva tem necessidade de aliados, pois tem inimigos. Dificilmente, uma comunidade se aventura em um conflito sem se proteger por intermédio de iniciativas diplomáticas. Com essa atitude, a comunidade primitiva constrói alianças e se torna mais forte. Essas alianças têm de ser rotineiramente fortificadas, pois a linha entre aliança e traição é tênue. As trocas são um meio para o estabelecimento de aliados.

As trocas são variadas e estão relacionadas às festas, às boas maneiras e às mulheres. As mulheres são verdadeiros objetos de troca entre as comunidades e instrumentos fundamentais para a construção de alianças. Isto é, a dominação masculina usa o sexo feminino para alcançar benefícios bélicos. As mulheres aceitam essa troca, pois acreditam que faz parte de uma cultura predeterminada e acabam naturalizando esse intercâmbio de corpos. Está aí a violência simbólica que Bourdieu discute em seus estudos. A fêmea se coisifica para cumprir interesses estipulados pelo "macho". 
Artigo original

Hegemonia - Revista Eletrônica do Programa de Mestrado em Direitos Humanos, Cidadania e Violência/Ciência Política do Centro Universitário Unieuro

ISSN: $1809-1261$

UNIEURO, Brasília, número 22 (Especial), 2017, pp. 74-97.

No quadro da aliança, a troca das mulheres adquire uma evidente importância política, o estabelecimento de relações matrimoniais entre grupos diferentes é um meio de concluir e reforçar a aliança política a fim de enfrentar nas melhores condições os inimigos inevitáveis. (CLASTRES, 2004, p.180)

E Clastres continua: " $\mathrm{Na}$ realidade, quando dois grupos entram em relação, eles de modo algum buscam trocar mulheres: o que querem é a aliança político-militar, e o melhor meio de chegar a isso é trocar mulheres". (CLASTRES, 2004, p.181). Portanto, ele ressalta o papel de objeto que a mulher tem na comunidade primitiva.

Conforme o exposto, o conceito de violência simbólica é fundamental para a compreensão da dominação masculina em relação à mulher. Trata-se de uma relação de poder na qual o dominante (homem) exerce uma soberania sobre o dominado (mulher), por exemplo. Esse domínio é invisível. Além disso, é aceito e naturalizado pelo oprimido. Isto é, a mulher não o reconhece como arbitrário e não o percebe como uma perpetuação de uma visão de mundo que solidifica ainda mais a opressão protagonizada pelo "macho da relação". Para Silva e Anjos,

Cabe afirmar ainda que dominação masculina se dá tanto no campo físico como no psicológico, este último se dá por meio da reprodução social, que na visão de Bourdieu verifica-se como o processo social pelo qual as culturas são reproduzidas através de gerações, sobretudo pela influência socializante de grandes instituições. A dominação masculina é um processo de construção social contra as mulheres, é uma forma de violência física, moral, psicológica como também simbólica que se reproduz ao longo da história da humanidade. Essa violência simbólica não consiste em algo concreto, mas sim uma violência que se dá de forma subjetiva e nas representações socioculturais. (SILVA; ANJOS, 2012, p. 2) 
Artigo original

Hegemonia - Revista Eletrônica do Programa de Mestrado em Direitos Humanos, Cidadania e Violência/Ciência Política do Centro Universitário Unieuro

ISSN: $1809-1261$

UNIEURO, Brasília, número 22 (Especial), 2017, pp. 74-97.

Freud (2011) ensina que a formação da família relacionou-se ao fato de a necessidade de satisfação genital estabelecer-se duradouramente. Assim o macho teve um motivo para conservar junto a si a fêmea ou, de modo mais geral, os objetos sexuais. Com essa dominação masculina, a fêmea, não querendo separar-se de seus rebentos indefesos, viuse obrigada, no interesse deles, a permanecer com o macho mais forte. Isso já na pré-história antropoide. "A vontade arbitrária do chefe da família primitiva, o pai, era irrestrita." (FREUD, 2011, p. 45)

Freud escreve que essa família alcança uma etapa subsequente, a da vida comunal, sob a forma de grupos de irmãos. Mesmo assim, o autor ainda aponta o caráter "objeto" da mulher e a mesma vivendo para os outros e não para ela.

A vitória sobre o pai havia ensinado aos filhos que uma associação pode ser mais forte que o indivíduo. A cultura totêmica baseia-se nas restrições que eles tiveram que impor uns aos outros, a fim de preservar o novo estado de coisas. Os preceitos do tabu constituíram o primeiro "direito". A vida humana em comum teve então um duplo fundamento: a compulsão ao trabalho, criada pela necessidade externa, e o poder do amor, que no caso do homem não dispensava o objeto sexual, a mulher, e no caso da mulher não dispensava o que saíra dela mesma, a criança. (FREUD, 2011, p. 45)

No artigo Participando do debate sobre mulher violência, Chauí ressalta que a ideologia que propaga a superioridade masculina é construída e reconstruída pelos dois sexos. De acordo com ela, as diferenças entre o homem e a mulher são hierarquizadas e têm como principal meta dominar e explorar, no caso, o sexo feminino. A hierarquização pode ser percebida da seguinte forma: "Definida como esposa, mãe e filha (ao contrário dos homens para os quais ser marido, pai e filho é algo que acontece apenas), as mulheres são definidas como seres para os outros e não como seres com os outros". (CHAUÍ, 1985, p.47). Conforme a filósofa, as mulheres atuam como cúmplices não conscientes dessa violência e mais: cooperam para que essa opressão se reproduza, pois são peças dessa engrenagem duradoura chamada dominação masculina. É como se o reconhecimento desse domínio fosse um fazer devoto por parte do sexo feminino, com ares divinos. 
Artigo original

Hegemonia - Revista Eletrônica do Programa de Mestrado em Direitos Humanos, Cidadania e Violência/Ciência Política do Centro Universitário Unieuro

ISSN: $1809-1261$

UNIEURO, Brasília, número 22 (Especial), 2017, pp. 74-97.

Coleira, um símbolo da dominação

Luma de Oliveira é uma ex-modelo, atriz e empresária brasileira. Atualmente com 52 anos, foi casada com o também empresário Eike Batista entre os anos de 1991 e 2004. Nascida no estado do Rio de Janeiro, Luma de Oliveira participou de algumas novelas, entre elas Meu bem, meu mal (1990), e de filmes, entre eles Os heróis trapalhões - uma aventura na selva (1988).

Se não teve papéis de destaque na televisão e no cinema, Luma de Oliveira foi personagem importante durante diversos anos nos desfiles de escolas de samba do Rio de Janeiro, na Marquês de Sapucaí. A história carnavalesca da hoje ex-modelo começou no final da década de 1980. Em 1987, teve sua primeira experiência como madrinha de bateria, desfilando pela Caprichosos de Pilares. Passou também pela Viradouro, Mangueira, Portela. Mas talvez foi na Tradição que Luma de Oliveira tenha causado mais polêmica. O ano: $1998^{8}$.

Vestindo uma fantasia preta, Luma de Oliveira foi à Marquês de Sapucaí ostentando uma coleira. No adereço, estava escrito "Eike", nome de seu marido à época. É óbvio que o episódio causou polêmica. Feministas a acusaram de apoiar a submissão da mulher ao homem. Luma de Oliveira enfrentou os julgamentos e teria destacado, entre outros pontos, que mulher submissa não desfilava no carnaval.

De acordo com o Dicionário online de Português, coleira é "correia ou corrente com que se cinge o pescoço dos animais”, cujo sinônimo é gargalheira. Ainda segundo o dicionário, gargalheira é uma espécie de "coleira de ferro ou madeira, com que se prendiam, para castigar, os escravos. E também: "coleira de pregos dos cães de gado e de fila". $\mathrm{Na}$ linguagem conotativa, o dicionário traz que gargalheira significa tirania e opressão.

Ao acessar o site wnm.sinonimos.com.br, encontra-se que coleira é sinônimo de gargalheira, que, por sua vez, tem os seguintes sinônimos: algema, grilhão, cadeia. A palavra "coleira" também tem "ajoujo" como sinônimo. Ajoujo é jugo, que no site aparece como dominação, comando, soberania, opressão, influência, submissão, entre outros.

Geralmente, a coleira é utilizada em cães. O objetivo do instrumento é controlar os passos do animal, guiá-lo, não o deixar ir longe demais. Em uma das pontas da coleira,

\footnotetext{
${ }^{8}$ Luma de Oliveira desfilou na Tradição em 1988, 1989, 1994, 1995, 1996, além de 1998.
} 
Artigo original

Hegemonia - Revista Eletrônica do Programa de Mestrado em Direitos Humanos, Cidadania e Violência/Ciência Política do Centro Universitário Unieuro

ISSN: 1809-1261

UNIEURO, Brasília, número 22 (Especial), 2017, pp. 74-97.

está o homem, que estrutura o caminho que o cão deve seguir; na outra, o animal, que vai e vem sob as ordens do indivíduo que está no comando da situação.

Por mais que Luma de Oliveira tenha falado que mulher submissa é aquela que não desfila no carnaval ou que a coleira fazia parte de sua fantasia de felina, o adereço utilizado no pescoço é também um símbolo e seu uso abriu brecha para as críticas das feministas.

Todo comportamento humano se origina no uso dos símbolos. Foi o símbolo que transformou nossos ancestrais antropoides em homens e os fez humanos. Todas as civilizações têm sido geradas e são perpetuadas pelo uso dos símbolos. É o símbolo que transforma um infantil de homo sapiens em ser humano. (...) Todo comportamento humano consiste, ou é dependente, do uso de símbolos. O comportamento humano é um comportamento simbólico. O comportamento simbólico é um comportamento humano. O símbolo é o universo da humanidade. (WHITE, 1944, p.1)

Para White, um símbolo é uma coisa, que tem um valor ou um significado. Esse valor ou significado é concedido ao símbolo por aqueles que o usam. Por exemplo, uma bandeira branca, que simboliza a rendição; uma pomba branca que significa a paz. White diz "coisa", pois um símbolo pode ter qualquer tipo de forma: um material, um objeto, uma cor, um som, um cheiro, um movimento de um objeto, um gosto.

Além desse aspecto, é possível depreender que há uma dominação masculina no uso da coleira, a partir do que Bourdieu entende como violência simbólica. Como já ressaltado, a violência simbólica (no caso, entre o masculino e o feminino) se constrói por intermédio de uma primazia concedida aos homens e isso se reflete em diversas situações na sociedade, como, por exemplo, na divisão sexual do trabalho, onde o "macho" realiza as tarefas consideradas mais nobres", cabendo à "fêmea" trabalhos domésticos, escondidos. A violência simbólica só existe, pois trata-se de um fenômeno relacional, que envolve poder. Os dominados contribuem para a criação, solidificação e perpetuação dos pontos de vista do dominante, mas não percebem arbitrariedades e veem o controle, a proibição, a opressão e 
Artigo original

Hegemonia - Revista Eletrônica do Programa de Mestrado em Direitos Humanos, Cidadania e Violência/Ciência Política do Centro Universitário Unieuro

ISSN: $1809-1261$

UNIEURO, Brasília, número 22 (Especial), 2017, pp. 74-97.

o privilégio dos homens como ocorrências naturais. "A violência simbólica não ocorre através de atos, da coação, mas pelo processo de submissão por parte dos dominados através do pensamento, das ideias e dos ideais assumidos pelos dominantes". (CASAGRANDE; PERUZZOLO, 2012, p. 241).

Ao desfilar com uma coleira na qual estava escrito o nome do marido, Luma de Oliveira classificou como natural utilizar um objeto cujo símbolo significa controle, submissão, dominação. É como se a modelo não pudesse dar os próprios passos, necessitando de alguém considerado o dono da relação para a conduzir até a dispersão da Marquês de Sapucaí. Além disso, ao declarar que mulher submissa é aquela que não desfila no carnaval ou que a coleira fazia parte da fantasia de felina, Luma de Oliveira naturaliza a dominação masculina, não a reconhecendo como uma arbitrariedade ou uma hierarquização. E isso acaba gerando uma perpetuação do comportamento.

Luma de Oliveira desfilou em 1998. Outras a seguiram e também ostentaram a coleira com o nome do parceiro. Esse foi o caso da modelo e atriz Viviane Araújo, que desfilou em 2005 no carnaval de São Paulo pela Mancha Verde com uma coleira na qual brilhava o nome do cantor Belo. Quando questionada sobre o uso do objeto, Viviane Araújo disse que foi ela mesma quem pediu para desfilar com a coleira. Afirmou, ainda, que desfilou pela Mancha Verde, pois era a escola de samba para a qual Belo torcia. Duas semanas antes do desfile, a modelo havia tatuado o nome do cantor no braço.

Em 2009, Miryan Martin disse ter homenageado o marido, o empresário Jorge Bugarin. A atriz foi à quadra da Viradouro, em Niterói, usando uma coleira no pescoço. Nela, estava o nome de seu parceiro. Outro exemplo foi o de Antônia Fontenelle, que desfilou pela Grande Rio na Marquês de Sapucaí, em 2015. Uma coleira, com as iniciais JC, em homenagem ao namorado, o funkeiro Jonathan Costa, fazia parte da fantasia da atriz.

De acordo com o site Ego, Jonathan Costa ressaltou que a coleira usada pela namorada não seria um símbolo de dominação e, sim, de amor. Ele afirmou, também, que soube da homenagem por meio da imprensa. Antônia pediu para a joalheira da Grande Rio, Claudia Bertine, confeccionar a joia em ouro rosé. No entanto, ao ver o tamanho do círculo que traz as iniciais de Jonathan Costa achou-o muito grande. A atriz disse aos repórteres que queria algo discreto e não essa "pizza enorme". No entanto, Antônia Fontenelle afirmou que se fosse menor não apareceria na avenida e que, por isso, teve de aceitar. 
Artigo original

Hegemonia - Revista Eletrônica do Programa de Mestrado em Direitos Humanos, Cidadania e Violência/Ciência Política do Centro Universitário Unieuro

ISSN: $1809-1261$

UNIEURO, Brasília, número 22 (Especial), 2017, pp. 74-97.

A reportagem relata que a atriz chegou ao sambódromo de mãos dadas com o namorado. Antônia Fontenelle chegou de roupão, mas mostrou para os repórteres do site a roupa "comportada" que usava por baixo e disse que a opção não tinha nada a ver com ciúme do namorado. No entanto, em seu discurso, ela se contradisse: "Ele não implicou com nada, mas sabe como é homem, né? Resolvi deixar tudo bem escondidinho para não dar problema".

Como se vê nas palavras de Antônia Fontenelle, há aceitação de uma situação de dominação. Isso é deduzível não apenas no uso da coleira, mas também na referência à roupa comportada que, sem perceber, foi obrigada a usar por que "sabe como homem é, né?"

Outro exemplo, esse bem mais recente, é o de Lexa (Léa Cristina Araújo da Fonseca), cantora e noiva de Mc Guimê (Guilherme Aparecido Dantas). Em 8 de outubro de 2016, a cantora usou uma coleira com o nome do companheiro durante sua coroação como musa da Vila Isabel, na quadra da escola de samba, no Rio de Janeiro.

A cantora diz que o acessório foi uma surpresa para o rapaz, que só descobriu o mimo quando as fotos dela foram publicadas na imprensa. "Quis fazer uma homenagem para o Guimê e me inspirei na Luma de Oliveira. Foi uma grande surpresa, ele não esperava", conta ela, animada. "Nos falamos pelo telefone até minutos antes de eu subir ao palco e ser anunciada como musa na quadra da Vila. Ele ficou louco querendo saber. Quando ele viu as fotos na imprensa, foi só alegria", diz Lexa. (GODINHO, 2016)

Portanto, foram trazidos exemplos em diferentes recortes temporais para ratificar uma perpetuação de domínio masculino. A tendência prosseguiu. Essa manutenção de soberania do "macho" em relação à "fêmea" acontece por intermédio de um poder simbólico, ou seja, um poder invisível, não reconhecido como arbitrário e que a parte dominada contribui, sem perceber, para sua naturalização e para a sua longevidade. Essa violência simbólica se caracteriza pelo controle, opressão, exclusão, domínio, atua sobre os corpos (no caso, os femininos) sem força física, como que por uma feitiçaria qualquer. 
Artigo original

Hegemonia - Revista Eletrônica do Programa de Mestrado em Direitos Humanos, Cidadania e Violência/Ciência Política do Centro Universitário Unieuro

ISSN: 1809-1261

UNIEURO, Brasília, número 22 (Especial), 2017, pp. 74-97.

Como podemos perceber a representação do homem como parte dominante da relação com a mulher em muito dos seguimentos da sua vida o que acaba sendo incorporado pelo senso comum como algo natural. Ora considere-se que as próprias mulheres acabam incorporando essa relação de poder em sua vida como algo que é irreversível, visto que já está naturalizado na sociedade, e não percebendo sua condição de dominada a mulher acaba reproduzindo essa forma de violência até mesmo com outras mulheres. (SILVA; ANJOS, 2012, p. 3)

Esses exemplos permitem a realização de uma indução incompleta ou científica, conforme destacado no início deste trabalho. Luma de Oliveira, Myrian Martin, Viviane Araújo, Antônia Fontenelle e Lexa são alguns casos citados e observados para abrir uma possibilidade de se dizer aspectos similares para o restante da categoria. Isto é, essas mulheres, mesmo sem perceberem, são uma parte que exemplifica esse poder simbólico/violência simbólica, assunto tão destacado por Bourdieu em seus estudos. Além disso, isso pode ser decisivo para que as arbitrariedades do homem sejam ilimitadas e para que a mulher continue a se configurar como um ser para os outros, como apontaram Freud e Chauí.

Outro ponto a ressaltar é que as mulheres trazidas no artigo são personalidades públicas. Têm fama e, às vezes, até aparecem em propagandas. O fato de elas ostentarem uma coleira com os nomes dos seus respectivos companheiros, além de contribuir, inconscientemente, para a perpetuação de uma dominação masculina, pode ter um efeito multiplicador dessa soberania dos homens, pois elas são celebridades e em algum ponto travestem-se de formadoras de opinião. Isso pode ser deduzido, pois, ao utilizar o adereço com o nome do seu "dono", Luma de Oliveira - considerada à época (1998) símbolo de beleza e de mulher bem-sucedida - "fez escola" e acabou influenciando outras mulheres, como, por exemplo, Miryan Martin e Antônia Fontenelle. Sem se esquecer do fato de que essas mulheres estavam usando a coleira durante o carnaval ou durante os ensaios para este, quando há uma grande exposição nas mídias nacional e internacional. 
Artigo original

Hegemonia - Revista Eletrônica do Programa de Mestrado em Direitos Humanos, Cidadania e Violência/Ciência Política do Centro Universitário Unieuro

ISSN: $1809-1261$

UNIEURO, Brasília, número 22 (Especial), 2017, pp. 74-97.

Considerações finais

O poder simbólico é, ao mesmo tempo, ubíquo e invisível. Está relacionado a um tipo de violência que não se utiliza da coação física. Além disso, essa violência conta, para a sua propagação, com quem deveria combatê-la, isto é, o dominado. A parte que é oprimida, sem perceber, trabalha para a continuidade do status quo. Os exemplos de uso de coleira em diferentes anos por parte das mulheres em pleno sambódromo corroboram isso.

Trata-se, porém, de uma situação contraditória. Ao mesmo tempo em que saem das suas casas para exibir seus corpos na Marquês de Sapucaí, como se fosse um grito de liberdade, as mulheres utilizam a coleira cujo símbolo é a antítese da autonomia, da emancipação. Com isso, o sexo feminino pode tornar-se cúmplice e partícipe de um cenário de dominação. Portanto, é necessário que haja uma relevante metamorfose das condições sociais de produção das tendências. Assim, será possível romper a relação de cumplicidade que essas vítimas da dominação simbólica - no caso, as mulheres - têm com os dominantes.

Levando-se em consideração o Mapa da Violência 2015 e seus assustadores dados e estatísticas, além dos conceitos aqui discutidos a partir dos estudos de Bourdieu, tem-se que é importante debater os dois tipos de violência: a que acontece como se fosse um passe de mágica; e aquela que, entre os anos de 1980 e 2013, redundou em 106.093 homicídios de mulheres no Brasil, conforme o levantamento utilizado neste trabalho.

\section{Referências}

ABRAMOVAY, Miriam; CUNHA, Anna Lúcia; CALAF, Priscila Pinto. Revelando tramas, descobrindo segredos: violência e convivência nas escolas. Brasília: Rede de Informação Tecnológica Latino-americana (RITLA), Secretaria de Estado de Educação do Distrito Federal (SEEDF), 2009.

BARROS, José D’Assunção. História Cultural: um panorama teórico e historiográfico. In: Textos de História. Vol. 11. $\quad \mathrm{N}^{\circ} \quad 1 / 2$ 2003. Disponível em: http://periodicos.unb.br/index.php/textos/article/viewFile/5925/4901. Último acesso: 17 de julho de 2016.

BOURDIEU, Pierre. O poder simbólico. Rio de Janeiro: Bertrand, 1989.

BOURDIEU, Pierre. A dominação masculina. 11.ed. Rio de Janeiro: Bertrand, 2012. 
Artigo original

Hegemonia - Revista Eletrônica do Programa de Mestrado em Direitos Humanos, Cidadania e Violência/Ciência Política do Centro Universitário Unieuro

ISSN: 1809-1261

UNIEURO, Brasília, número 22 (Especial), 2017, pp. 74-97.

CASAGRANDE, Magnos Cassiano; PERUZZOLO, Adair Caetano. O Fenômeno da violência e sua relação com os meios de comunicação, comunicação humana e Estado. Revista do Laboratório de Estudos da Violência da UNESP/Marília, Edição 10, p. 237-255, dez. 2012. Disponível em: <http://www2.marilia.unesp.br/ revistas/index.php/levs/article/view/2648/2078>. Último acesso: 15 de abril de 2017.

CHARTIER, Roger. A História Cultural entre Práticas e Representações. 2.ed. Algés (Portugal): Difel, 2002.

CHARTIER, Roger. O Mundo como Representação. In: Revista das Revistas. Estudos Avançados. São Paulo. Vol.5. no 11, p. 173-191, jan./abr. Jan./Apr. 1991. Disponível em: http://www.revistas.usp.br/eav/article/view/8601/10152. Último acesso: 23 de julho de 2016.

CHAUÍ, Marilena. Participando do debate sobre mulher e violência. In: Várias autoras: Perspectivas Antropológicas da Mulher, no 4, Rio de Janeiro, Zahar Editores, 1985. Páginas 25-62.

CLASTRES, Pierre. Arqueologia da violência - pesquisas de antropologia politica. São Paulo: Cosac \& Naify, 2004.

FREUD, Sigmund. O mal-estar na civilização. São Paulo: Penguin Classics \& Companhia das Letras, 2011.

HOBSBAWN, Eric. Era dos extremos - o breve século XX (1914-1991). 2.ed. São Paulo: Companhia das Letras, 1995.

JODELET, Denise. Representações sociais: um dominio em expansão. In: JODELET, Denise (Org.). As representações sociais. Rio de Janeiro: Ed UERJ, 2001.

LARAIA, Roque de Barros. Cultura - um conceito antropológico. 11.ed. Rio de Janeiro: Jorge Zahar, 1997.

MARCONI, Marina de Andrade. LAKATOS, Eva Maria. Fundamentos de metodologia científica. 5.ed. São Paulo: Atlas, 2003.

PESAVENTO, Sandra Jatahy. História \& História Cultural. 3.ed. Belo Horizonte: Autêntica, 2012.

PORTO, Maria Stela Grossi. Brasilia, uma cidade como as outras? Representações Sociais e Práticas de Violência. In: Sociedade e Estado, Brasília. Vol. 24, no 3, p. 797-826, set./dez. 2009. Disponível em: $\quad$ http://www.scielo.br/scielo.php?pid=S010269922009000300008\&script=sci_abstract\&tlng=pt. Último acesso: 23 de julho de 2016. 
Artigo original

Hegemonia - Revista Eletrônica do Programa de Mestrado em Direitos Humanos, Cidadania e Violência/Ciência Política do Centro Universitário Unieuro

ISSN: 1809-1261

UNIEURO, Brasília, número 22 (Especial), 2017, pp. 74-97.

SILVA, Maria; ANJOS, Edjania. Dominação masculina: a violência simbólica contra a mulher nas letras de músicas brasileiras. $17^{\circ}$ Encontro Nacional da Rede Feminista e Norte e Nordeste de Estudos e Pesquisa sobre a Mulher e Relações de Gênero (2012). Último acesso: 15 de abril de 2017.

WAISELFISZ, Julio Jacobo. Mapa da violência 2015 - Homicídio de mulheres no Brasil. Brasília: Flacso, 2015.

WEBER, Max. Economia e sociedade: fundamentos da sociologia compreensiva. Volume 2. Brasília: UnB, 1999.

WHITE, Leslie. The symbol: the origin and basis of human behavior. In: ETC: A review of general semantics. Volume 1, number 4, 1944. Disponível em:http://www.generalsemantics.org/wp-content/uploads/2011/05/gsb72-white.pdf. Último acesso: 10/07/2016.

Sites

MARTINEZ, Léo; TECIDIO, Luciana. Antonia Fontenelle mostra 'coleira' em homenagem a namorado. 2015.2 Disponível em: http://ego.globo.com/carnaval/2015/noticia/2015/02/antonia-fontenelle-mostra-coleiraem-homenagem-namorado.html. Último acesso: 23 de julho de 2016.

GODINHO, Raphael. Lexa fala sobre coleira escrito Guimê e figurino de R\$20 mil: 'Homenagem'. Úlimo acesso: 15 de abril de 2017.

O TEMPO. Miryan Martin usa coleira com o nome do marido. 2009. Disponível em: http://www.otempo.com.br/divers\%C3\%A3o/miryan-martin-usa-coleira-com-o-nomedo-marido-1.123387. Último acesso: 23 de julho de 2016.

TERRA. Viviane Araújo desfila com Belo escrito na coleira. 2005. Disponível em: http://noticias.terra.com.br/interna/0,OI467023-EI4518,00.html. Último acesso: 23 de julho de 2016. 